\title{
Salvage Conformal Radiotherapy for Biochemical Recurrent Prostate Cancer after Radical Prostatectomy
}

\author{
Carlos R. Monti, Ricardo A. Nakamura, Robson Ferrigno, Aristides Rossi Jr, Neusa S. \\ Kawakami, Felipe A. Trevisan
}

Radiotherapy Department, Radium Oncology Institute, Campinas, Sao Paulo, Brazil

\begin{abstract}
Objective: Assess the results of salvage conformal radiotherapy in patients with biochemical failure after radical prostatectomy and identify prognostic factors for biochemical recurrence and toxicity of the treatment.

Materials and Methods: From June 1998 to November 2001, 35 patients were submitted to conformal radiotherapy for $\mathrm{PSA} \geq 0.2 \mathrm{ng} / \mathrm{mL}$ in progression after radical prostatectomy and were retrospectively analyzed. The mean dose of radiation in prostatic bed was of $77.4 \mathrm{~Gy}(68-81)$. Variables related to the treatment and to tumor were assessed to identify prognostic factors for biochemical recurrence after salvage radiotherapy.

Results: The median follow-up was of 55 months (17-83). The actuarial survival rates free of biochemical recurrence and free of metastasis at a distance of 5 years were $79.7 \%$ e $84.7 \%$, respectively. The actuarial global survival rate in 5 years was $96.1 \%$. The actuarial survival rate free of biochemical recurrence in 5 years was $83.3 \%$ with PSA pre-radiotherapy $\leq 1$, $100 \%$ when $>1$ and $\leq 2$, and $57.1 \%$ when $>2(\mathrm{p}=0.023)$. Dose $>70 \mathrm{~Gy}$ in $30 \%$ of the bladder volume implied in more acute urinary toxicity $(\mathrm{p}=0.035)$. The mean time for the development of late urinary toxicity was 21 months $(12-51)$. Dose $>55 \mathrm{~Gy}$ in $50 \%$ bladder volume implied in more late urinary toxicity $(\mathrm{p}=0.018)$. A patient presented late rectal toxicity of 2nd grade.

Conclusions: Conformal radiotherapy showed to be effective for the control of biochemical recurrence after radical prostatectomy. Patients with pre-therapy PSA $\leq 2 \mathrm{ng} / \mathrm{mL}$ have more biochemical control.
\end{abstract}

Key words: prostatic neoplasms; prostate-specific antigen; salvage therapy; radiotherapy

Int Braz J Urol. 2006; 32: 416-27

\section{INTRODUCTION}

Amongst the treatments used for the salvage of patients with biochemical recurrence after radical prostatectomy that can offer cure to the patients, radiotherapy is the most interesting therapeutic modality, if not, the only one (1). The rates of biochemical control in 5 years with salvage radiotherapy vary from $10 \%$ to $58 \%(2,3)$ due to the great difficulty in selecting patients with non-metastatic disease after radical prostatectomy. It is not yet established in literature the best moment to offer radiotherapy, either as an adjuvant or as a salvage therapy, which should be the extension of radiotherapy field, the dose of radiation, the use of neoadjuvant, concomitant and/or adjuvant of androgenic suppression, and which patients distant disease free that would benefit of loco-regional treatment. Retrospective studies $(3,4)$ have observed better recurrence results of adjuvant radiotherapy over salvage radiotherapy in high risk patients. Bolla et al. 
(5), in a randomized study comparing adjuvant radiotherapy or not with radiotherapy in high risk recurrence patients after radical prostatectomy, have observed a superiority in adjuvant treatment in relation to the survival rate free of biochemical recurrence and disease progression. Even though there is an occurrence of more toxicity grade 2 and 3 in the group of adjuvant treatment, the late toxicity greater or equal to grade 3 occurred in only $4.2 \%$ of the patients. The present article aims at reporting the results of conformal salvage radiotherapy in prostate cancer with biochemical recurrence after radical prostatectomy performed in a sole institution, and identify variables associated to biochemical control and the toxicity of the treatment.

\section{MATERIALS AND METHODS}

\section{Patient's Population}

From June 1998 to November 2001, 35 patients were submitted to conformal salvage radiotherapy for PSA $\geq 0.2 \mathrm{ng} / \mathrm{mL}$ in progression after radical prostatectomy for prostate adenocarcinoma in a sole institution, and they were retrospectively analyzed. All patients were staged according to the staging system of 2002 American Joint Committee on Cancer. All had bone scintigraphy without the evidence of metastatic disease previous to the salvage radiotherapy. All patients signed an informed consent previous to treatment.

\section{Patients Characteristics before Salvage Radiotherapy}

Median age was 65 years (52-74). Median pre-radiotherapy PSA was $1.5 \mathrm{ng} / \mathrm{mL}(0.2-8.98)$. Eight patients had a nodule in prostatic fossa at digital rectal examination and/or at the computerized tomography. The median time between biochemical recurrence after surgery and the radiotherapy was 2.3 months, which is low, being possible to indicate distant disease. All patients were considered as a sole high-risk group for systemic dissemination, for they presented biochemical recurrence, and thus, 5 patients that did not have pathologic results of radical prostatectomy were included in the study; for statistical analysis, these patients were considered as negative margin so that radiotherapy could not benefit. Urinary incontinence and urethral stenosis were considered as postoperative complications. Other patients' characteristics are listed in Table-1.

\section{Characteristics of Salvage Treatment}

Fourteen patients received neoadjuvant hormone therapy, 17 at the same time and 2 adjuvant in relation to radiotherapy. For salvage radiotherapy, patients were oriented to ingest $300 \mathrm{~mL}$ of liquid and void 1 hour before the simulation and treatment procedures. Patients were simulated in dorsal decubitus, in a CTE General Electric helicoidal tomography with venous and urethra contrast, with $5 \mathrm{~mm}$ thickness. Images were acquired by the software "Med Crane". The treatment targets were delineated in the tomography slices in the following way: a) prostatic bed - delineated the anastomotic junction between the membranous urethra and the vesical trigone; b) seminal vesicles bed - delineated seminal residual vesicles or the region that supply seminal vesicles; c) drainage - delineated lymph nodes of the internal and external iliac veins starting from the caudal part of the sacroiliac articulation, and obturatory lymph nodes, excluding lateral perirectal lymph nodes. As margins for target movement and positioning errors $10 \mathrm{~mm}$ were given in all dimensions and $3 \mathrm{~mm}$ afterwards. The risk organs were outlined in the following way: a) bladder - outlined all its volume through the external muscular layer; b) rectum - outlined its entire volume trough the external layer, from the anal-rectal transition zone until the rectal-sigmoid transition. Energies of 6 or $15 \mathrm{MeV}$, and 5 fields of radiation were utilized. Radiotherapy treatment was divided in phases: in the first phase the pelvis, the seminal vesicle region and the prostatic bed were irradiated; afterwards, the volume of treatment was restricted to the seminal vesicle region and to the prostatic bed; and in the end, the field of treatment has embodied only the prostatic bed. When no pelvic irradiation occurred, treatment was performed in only 2 phases, the irradiation of the seminal vesicle region the prostatic bed, and afterwards only the prostatic bed (Figure1). Pelvic irradiation, the doses in the seminal vesicle 
Table 1 - Characteristics of patients submitted to salvage conformal radiotherapy in biochemical recurrence after radical prostatectomy.

\begin{tabular}{lcc}
\hline Variable & Category & N Patients $(\%)$ \\
\hline Positive Margin & Yes & $15(42.9)$ \\
Postoperative tumor extension & No & $20(57)$ \\
& T2a & $5(14.3)$ \\
& T2b-T2c & $10(28.6)$ \\
Gleason score & T3a-T3b & $15(42.9)$ \\
& Undetermined & $5(14.3)$ \\
& $\leq 6$ & $20(57.1)$ \\
PSA pre-radiotherapy & 7 & $9(25.7)$ \\
& $\geq 8$ & $4(11.4)$ \\
Postoperative complications & Undetermined & $2(5.7)$ \\
& $\leq 1$ & $12(34.3)$ \\
Co-morbidity & $1-\leq 2$ & $11(31.4)$ \\
& $>2$ & $12(34.3)$ \\
Time between surgery and radiotherapy & Yes & $13(37.1)$ \\
& No & $22(62.9)$ \\
& Yes & $11(31.4)$ \\
& No & $24(68.6)$
\end{tabular}

region and in the prostatic bed were performed according to the radiotherapist decision. Fifteen patients received pelvic radiotherapy without any association to hormone therapy. Eight received pelvic radiotherapy concomitant to hormone therapy. The dose of median radiotherapy in pelvis for the patients that were submitted to pelvic irradiation was 4840 cGy (4680-5040). Afterwards information regarding the treatment was transferred to the linear accelerator Mevatron MD-2 Siemens and the treatment was performed with a dose 180 cGy per day, 5 days a week. Other characteristics of the treatment are listed on Table-2.

\section{Patients Follow-up}

After salvage radiotherapy patients were monitored with total serial PSA between 3 and 6 months, and image studies were requested when specific complaints were filed. All patients were contacted by telephone to update data regarding bio- chemical control and toxicity at the moment of the analysis.

Acute toxicity was considered up to 3 months after the end of the salvage radiotherapy. Acute and late toxicities were assessed for rectum and bladder and were graded according to "Common Terminology Criteria for Adverse Effects version 3" (6).

Biochemical failure was considered after 3 consecutives increases of the total PSA (7) or the beginning of anti-androgen therapy due to total PSA increase after salvage radiotherapy.

\section{Statistical Analysis}

Descriptive statistics methods based on frequency tables for qualitative variables and measurement calculation for central tendency and dispersion were utilized, besides the Kaplan-Meier method, when applied to quantitative variables. Analytical statistics utilized for the comparison of proportions either the qui-square method or Fisher's exact test, ac- 

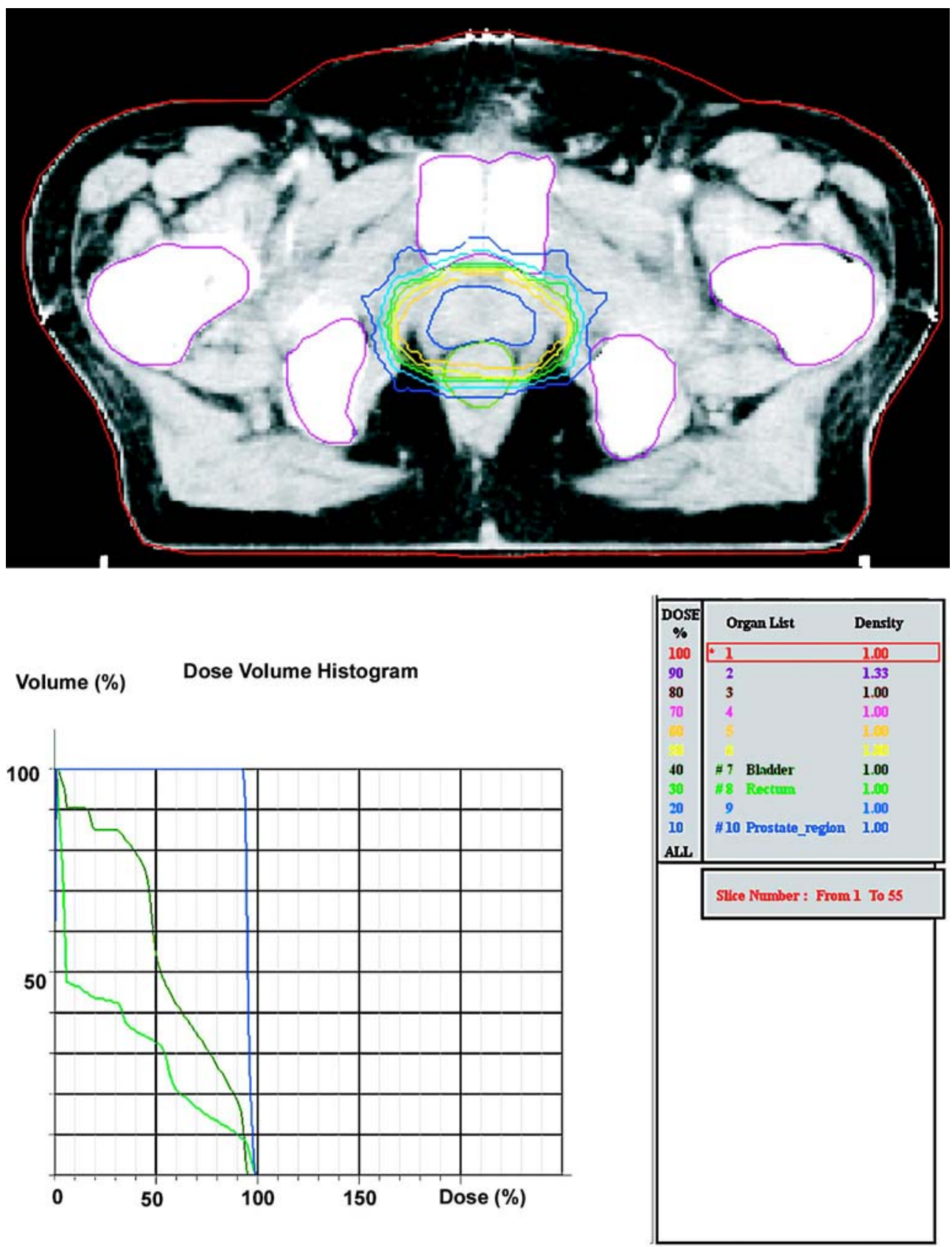

Figure 1 - Prostatic bed outline in axial cut and histogram dose volume of the target volume and risk organs.

cording to the case, in contingency tables. For the association among quantitative variables the Pearson correlation coefficient was utilized. The comparison of quantitative variables among the groups considered in each case was done based on the log-rank. P < 0.05 was considered statically significant. 
Table 2 - Characteristics of salvage conformal radiotherapy in biochemical recurrence after radical prostatectomy.

\begin{tabular}{|c|c|}
\hline Variable & $\begin{array}{c}\text { Median } \\
\text { (cGy) } \\
\text { Variation }\end{array}$ \\
\hline Radiation dose at the seminal vesicle region & $\begin{array}{c}6660 \\
4680-7740\end{array}$ \\
\hline Radiation dose at the prostatic bed region & $\begin{array}{c}7740 \\
6840-8100\end{array}$ \\
\hline Radiation dose at $50 \%$ of the bladder & $\begin{array}{c}5482 \\
2246-7137\end{array}$ \\
\hline Radiation dose at $30 \%$ of the bladder & $\begin{array}{c}6580 \\
3254-7709\end{array}$ \\
\hline Radiation dose at $50 \%$ of the rectum & $\begin{array}{c}4832 \\
1759-6880\end{array}$ \\
\hline Radiation dose at $25 \%$ of the rectum & $\begin{array}{c}6430 \\
2920-7702\end{array}$ \\
\hline Radiation dose at $15 \%$ of the rectum & $\begin{array}{c}6937 \\
3618-7979\end{array}$ \\
\hline Radiation dose at $5 \%$ of the rectum & $\begin{array}{c}7403 \\
5783-8176\end{array}$ \\
\hline Time of treatment with radiotherapy & $\begin{array}{c}2.4 \\
1.2-3.3\end{array}$ \\
\hline
\end{tabular}

\section{RESULTS}

\section{Biochemical Control}

Mean follow-up was 55 months (17-83). Actuarial survival rate of biochemical recurrence and free of metastasis in 5 years were $79.7 \%$ and $84.7 \%$, respectively (Figures-2 and 3). The mean time for the development of biochemical recurrence after radiotherapy was 15 months, and there was no biochemical recurrence after 36 months. One patient died due to prostate cancer 48.1 months after radiotherapy.
Actuarial global survival rate in 5 years was $96.1 \%$.

Actuarial survival rate free of biochemical recurrence in 5 years was $83.3 \%$ when pre-radiotherapy PSA $\leq 1,100 \%$ when pre-radiotherapy PSA $>1$ and $\leq 2$, and $57.1 \%$ when pre-radiotherapy PSA $>2(\mathrm{p}=0.023)$ (Figure-4). Neoadjuvant hormone therapy either concomitant or adjuvant, co-morbidity, radiation dose in seminal vesicle and prostrate bed, age, radiation treatment time and time between surgery and radiotherapy did not influence biochemical control. Other variables analyzed were not significant for the biochemical control (Table-3).

\section{Acute and Late Toxicities}

Four patients presented acute urinary toxicity grades 2 and 3 (Table-4). Dose $>70$ Gy at $30 \%$ of the bladder volume implied in a more acute urinary toxicity $(\mathrm{p}=0.035)$.

Six patients (17\%) presented late urinary toxicity grades 2 and 3 (Table-4). One patient with late urinary retention and the patient with late hematuria did not have their complications solved until the moment of the analysis. Actuarial survival rate free from late urinary toxicity grade 2 and 3 in 5 years was $80.6 \%$. The mean time for the development of late urinary toxicity was of 21 months (12-51). Dose $>55$ Gy at $50 \%$ bladder volume implied in a higher late toxicity $(\mathrm{p}=0.018)$ (Figure-5). Treatment time with radiation did not influence acute urinary toxicity, however, patients that received radiotherapy in a shorter space of time presented more late urinary toxicity $(\mathrm{p}=0.019)$. In the multivariate linear regression analysis, only dose $>55$ Gy at $50 \%$ of the bladder volume was significant for late urinary toxicity $(\mathrm{p}=$ 0.021). Age, co-morbidity, neoadjuvant hormone therapy, radiation dose in seminal vesicle and prostrate bed did not influence the toxicity of the treatment. Other variables analyzed were not relevant for acute and late urinary toxicity (Table-5).

\section{DISCUSSION}

Radical prostatectomy is a highly efficient treatment in localized prostate cancer therapy. However, disease-free survival rate is only $37-70 \%$ when 


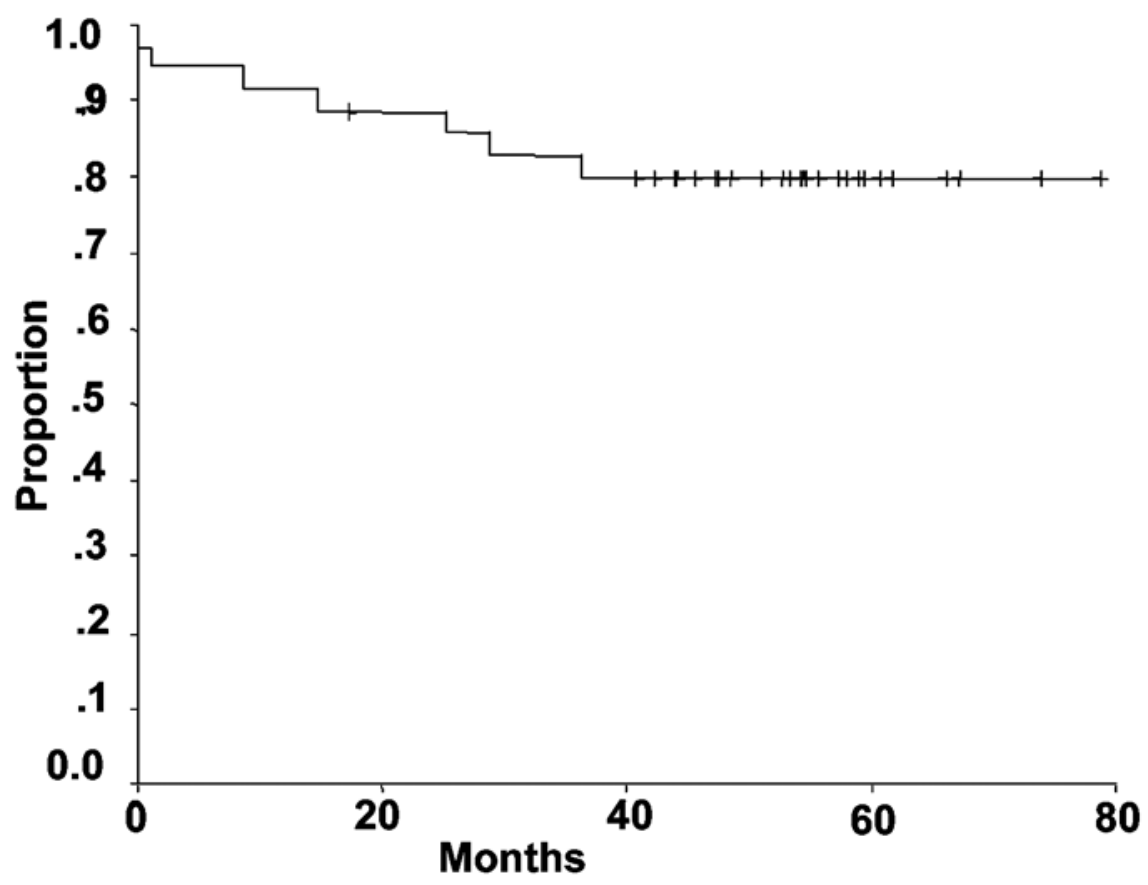

Figure 2 - Actuarial survival rate free from biochemical recurrence after salvage conformal radiotherapy.

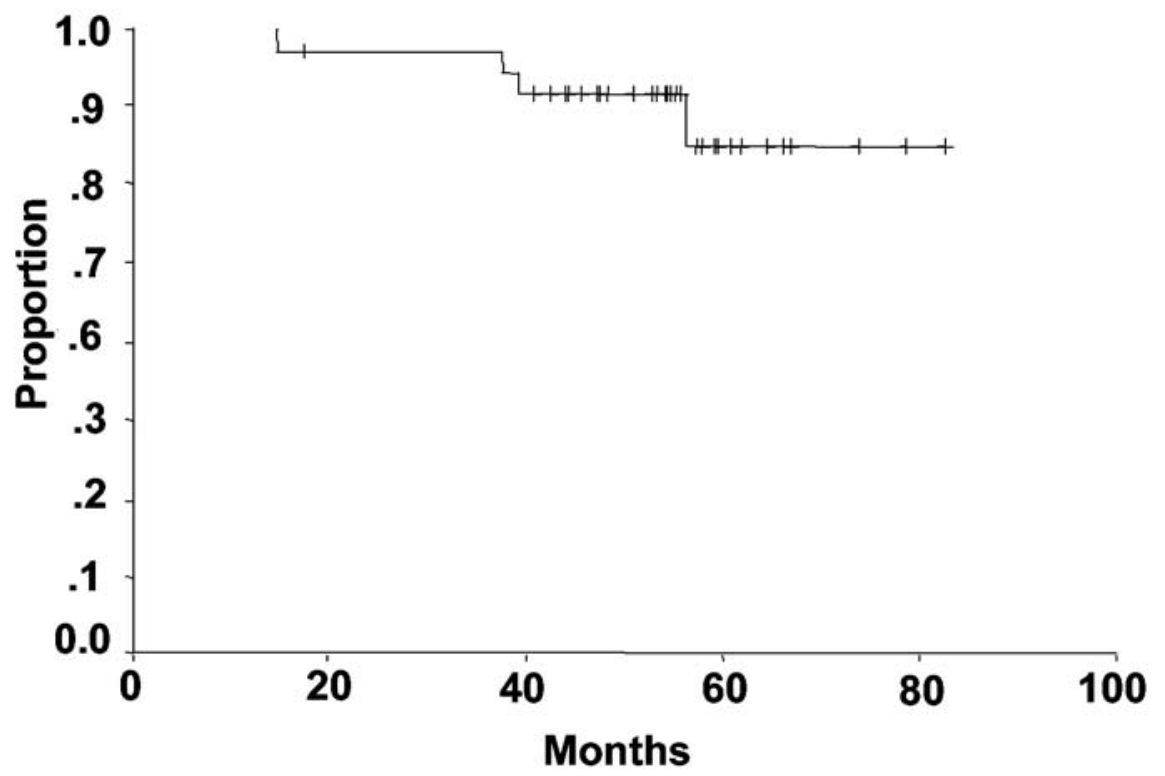

Figure 3 - Actuarial survival rate free from distant metastasis after salvage conformal radiotherapy. 


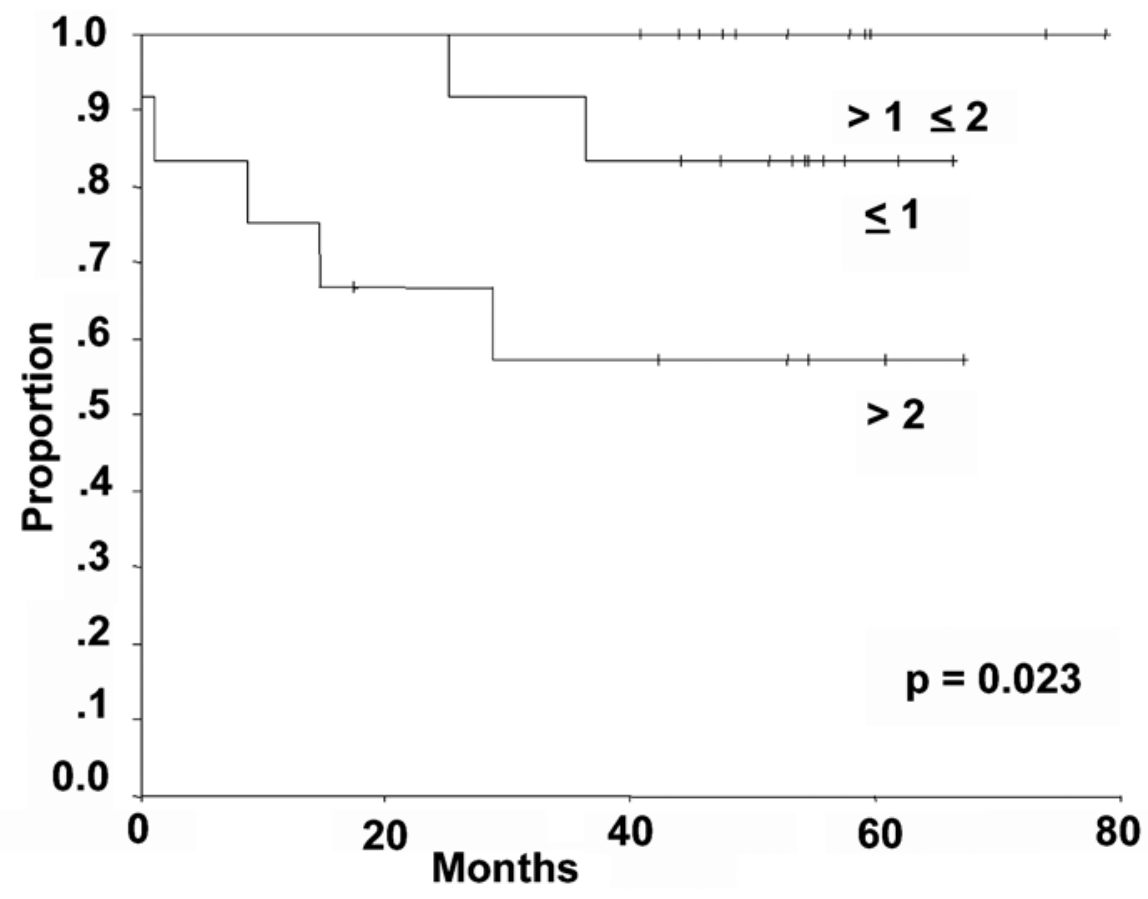

Figure 4 - Actuarial survival rate free from biochemical recurrence after survival conformal radiotherapy for groups of patients with pre-radiotherapy $P S A \leq 1,>1 \leq 2,>2 \mathrm{ng} / \mathrm{mL}$.

Table 3 - Univariate analysis of variables associated to biochemical recurrence free survival rate in 5 years after salvage conformal radiotherapy.

\begin{tabular}{lccc}
\hline Variable & Category & $\begin{array}{c}\text { Probability of Biochemical } \\
\text { Recurrence in 5 Years }\end{array}$ & p Value \\
\hline Positive margin & Yes & $80 \%$ & 0.967 \\
Postoperative tumor stage & No & $79.4 \%$ & 0.148 \\
& $\leq$ T2c & $80 \%$ & 0.288 \\
Gleason score & T3a-T3b & $66.7 \%$ & 0.023 \\
Pre-radiotherapy PSA & $\leq 6$ & $84.7 \%$ & \\
& $\geq 7$ & $69.2 \%$ & 0.679 \\
Prostatic nodule & $\leq 1$ & $103 \%$ & 0.788 \\
Radiotherapy in pelvis & $1-\leq 2$ & $57.1 \%$ & \multirow{2}{*}{0.482} \\
Radiotherapy in pelvis associated & $>2$ & $81 \%$ & \\
to hormone therapy & Yes & $78.2 \%$ & $83.3 \%$ \\
\hline
\end{tabular}


Table 4-Late and acute toxicities.

\begin{tabular}{lll}
\hline Acute Toxicity & Hematuria grade 2 & 1 \\
& Dysuria grade 2 & 1 \\
& Urinary incontinence grade 2 & 1 \\
& Urinary retention grade 3 & 1 \\
& Rectal bleeding grade 1 & 1 \\
Late Toxicity & Hematuria grade 2 & 1 \\
& Dysuria grade 2 & 1 \\
& Urinary incontinence grade 2 & 1 \\
& Urinary retention grade 3 & 3 \\
& Rectal bleeding grade 2 & 1 \\
\hline
\end{tabular}

there is extension of the disease beyond the prostatic capsule or there is impossibility of surgery with negative margins (8). We estimate that $65 \%$ of the patients with biochemical recurrence after prostatectomy will develop bone metastasis in 10 years (9). However, some patients with total PSA in progression after a radical prostatectomy will have a disease initially confined to the pelvis with a subsequent systemic dis- semination. Salvage radiotherapy becomes interesting for this group of patients, being the best-studied treatment that can offer cure (1).

In our country there are no statistic data on the number of patients sent to a second treatment with radiotherapy. However, in the United States, less than $50 \%$ receive salvage radiotherapy treatment (9). There is a disseminated perception that the majority of biochemical recurrent patients have a hidden metastatic disease impeding any well-succeeded local salvage therapy, especially if the recurrence is precocious. This is because some series of salvage radiotherapy for biochemical failure have reported recurrence-free survival rates as low as $0 \%$ to $19 \%$ (4). Another current conception is that postoperative radiotherapy can cause actinic toxicities as high as $41 \%$ (10). However, conformal techniques have minimized bladder and rectum volume included in the field of treatment with radiation and allow the liberation of high doses of radiation with acceptable toxicity. Even though conformal salvage radiotherapy studies in biochemical recurrent prostate cancer are few, biochemical and

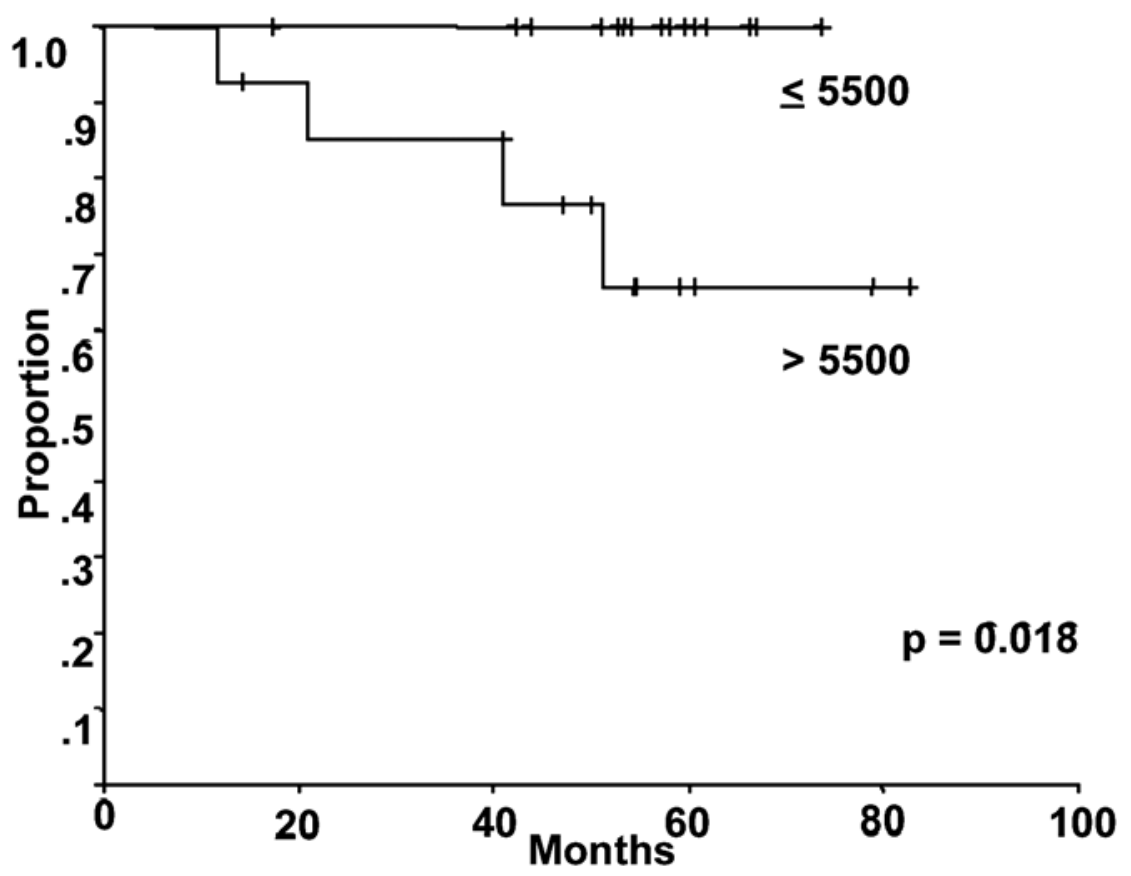

Figure 5 - Actuarial survival rate free from late urinary toxicity grades 2 and 3 after salvage conformal radiotherapy due to the radiation dosage of $5500 \mathrm{cGy}$ in $50 \%$ of the bladder volume. 
Table 5 - Univariate analysis of variables associated to late urinary toxicity-free survival rate grades 2 and 3 after survival conformal radiotherapy in 5 years.

\begin{tabular}{|c|c|c|c|}
\hline Variable & Category & $\begin{array}{l}\text { Probability of Late Urinary Toxicity- } \\
\text { Free Survival Rate in } 5 \text { years }\end{array}$ & p Value \\
\hline Post-surgery complications & $\begin{array}{l}\text { Yes } \\
\text { No }\end{array}$ & $\begin{array}{l}67.3 \% \\
90 \%\end{array}$ & 0.142 \\
\hline Radiotherapy in pelvis & $\begin{array}{l}\text { Yes } \\
\text { No }\end{array}$ & $\begin{array}{l}76.0 \% \\
90 \%\end{array}$ & 0.407 \\
\hline $\begin{array}{l}\text { Radiotherapy in pelvis associated to hormone } \\
\text { therapy }\end{array}$ & $\begin{array}{l}\text { Yes } \\
\text { No }\end{array}$ & $\begin{array}{l}88.8 \% \\
76.9 \%\end{array}$ & 0.560 \\
\hline Radiation dose in $50 \%$ bladder volume & $\begin{array}{l}\leq 55 \mathrm{~Gy} \\
>55 \mathrm{~Gy}\end{array}$ & $\begin{array}{l}100 \% \\
65.6 \%\end{array}$ & 0.018 \\
\hline Radiation dose in $30 \%$ bladder volume & $\begin{array}{l}\leq 70 \mathrm{~Gy} \\
>70 \mathrm{~Gy}\end{array}$ & $\begin{array}{l}88.2 \% \\
76.1 \%\end{array}$ & 0.314 \\
\hline
\end{tabular}

toxicity control results have revealed long-lasting responses with low toxicity $(3,11)$. Katz et al. (11) have reported actuarial biochemical control of $77 \%$ in 4 years with late urinary toxicity grade 2 and 3 in 4 years $9 \%$ and $10 \%$, respectively. Tsien et al. (3) have reported biochemical control rates in 5 and 8 years of $58 \%$ and $37 \%$, with rectal and urinary complications probability rates $\geq$ grade 2 in 5 years of $6.3 \%$ and $8.9 \%$, respectively. The present series have obtained similar actuarial rates in relation to the disease-free, metastasis-free and global survival rate, with acceptable acute and late complications rate and similar to the studies with the conformal technique and high radiation doses $(3,11)$.

Katz et al. (11) reported that patients with positive margins have the smaller probability of biochemical control with salvage radiotherapy, however, median doses used in biochemical recurrence and in tumor recurrence in their series were $66.6 \mathrm{~Gy}$ and $70.2 \mathrm{~Gy}$, respectively. In the present series, positive margins or the presence of a palpable nodule in prostatic fossa do not influence biochemical failure, probably because of the high radiation dose liberated in prostatic bed (median dose of 77.4 Gy).

Efficient salvage radiotherapy dose for biochemical control after surgery has not been established in literature. In patients submitted to radiotherapy exclusively for prostate cancer with locally advanced disease, high PSA and Gleason value have benefited from higher radiotherapy doses $(\geq 75.6 \mathrm{~Gy})(12,13)$. In salvage radiotherapy, we have also suggested that higher radiation doses (> 64.8 Gy) have obtained a better biochemical control (14). Series with high radiation doses have reported biochemical recurrencefree actuarial survival rates in 4 and 5 years of $77 \%$ (11) and $81 \%$ (15) in selected patients. In the present series, radiation dose was not a significant factor for the control of the disease, probably because the median radiation dose in prostatic bed was high and only 2 patients received a dosage inferior to $70 \mathrm{~Gy}$.

Roach et al. (16) have reported that in prostate cancer patients not operated, pelvic radiotherapy associated to hormone therapy have proportioned a greater biochemical recurrence-free survival rate in patients with more that $15 \%$ risk of lymph node involvement, suggesting that pelvic lymph node prostate cancer is sensible to radiation when utilized at the same time as hormone therapy. The extension of the radiotherapy field in post-surgery salvage is not established in retrospective studies and not even there are randomized studies proving or not its benefit. However, lymph nodes attacked by prostate cancer 
have been reported as post-surgery PSA production sources and based on Roach et al. findings (16), concomitance between radiotherapy and hormone therapy can benefit those patients. In the present series, the use of pelvic radiotherapy and hormone therapy did not influence biochemical control, probably by the relative small number of patients.

The extension of the disease to seminal vesicles has been reported as an important prognostic factor to biochemical failure after salvage radiotherapy in post-surgery biochemical failure (11). In the present series, it was not possible to correctly assess the importance of the seminal vesicles invasion by prostate cancer due to pathological charts that did not inform the situation of the seminal vesicles or the failure to completely remove them during surgery. Radiation dose was high at the seminal vesicles region with a median dose of $6660 \mathrm{cGy}$, and probably adequate for the control of the disease in this region, not influencing biochemical control.

Many series have associated pre-radiotherapy PSA values higher than $1 \mathrm{ng} / \mathrm{mL}$ and higher than 2 $\mathrm{ng} / \mathrm{mL}$ with less probability of biochemical control $(14,17)$. In this series pre-radiotherapy PSA $\leq 1$ and between 1 and 2 were presented as similar groups, not revealing significant statistical difference between them, even though there was a difference in percentage. However, pre-radiotherapy PSA $>2 \mathrm{ng} / \mathrm{mL}$ implied in a higher biochemical recurrence $(\mathrm{p}=0.023)$, suggesting that the most benefit is achieved when the treatment is preformed precociously.

Gleason value is being considered a factor related to biochemical recurrence in patients submitted to salvage radiotherapy in post-surgery biochemical recurrence (3). The reported series did not find any association between Gleason value and biochemical failure.

Adjuvant conventional radiotherapy series or in salvage of post-surgery biochemical recurred prostate cancer have reported toxicity grade 3 varying from $5 \%$ to $14 \%(18,19)$. Maier et al. (15) have treated 149 patients with a median dose of $68 \mathrm{~Gy}$ and 21 patients with a dose of $78 \mathrm{~Gy}$, and reported $19 \%$ and $33 \%$ gastrointestinal and genitourinary toxicity grade 2 , and $3 \%$ and $6 \%$ of gastrointestinal and genitourinary toxicity grade 3 , respectively. Katz et al. (11) reported annual actuarial rates in 4 years of late genitourinary toxicity grades 2 and 3 of $9 \%$ and $10 \%$, respectively, and late gastrointestinal toxicity grades 2 and 3 of $12 \%$ and $0 \%$, respectively. Tsien et al. (3) reported urinary and rectal complication probability rates $\geq$ grade 2 in 5 years of $6.3 \%$ and $8.9 \%$, respectively. In the present series, a patient has presented acute rectal toxicity grade 1 and a late rectal toxicity grade 2 , not allowing any statistical analysis. Margins of $3 \mathrm{~mm}$ in prostatic bed for the rectum to compensate organ movement and positioning errors during radiotherapy applications have probably helped low rectal morbidity and did not compromise biochemical control. Acute and late genitourinary toxicities were acceptable, even though not irrelevant. However, we can identify which dose $>70$ Gy in $30 \%$ bladder volume implied in a higher acute urinary toxicity, and dose $>55$ Gy in $50 \%$ of the bladder volume implied in a higher late urinary toxicity, suggesting that the restriction of radiation dose in these volumes would minimize the radiotherapy effects. In the present series, a shorter time of treatment with radiation resulted in higher late genitourinary toxicity; however, this factor was not relevant to multivariate linear regression analysis. This finding has not been found in other salvage radiotherapy series in literature, being possible to be a sample error.

\section{CONCLUSION}

Conformal radiotherapy showed to be effective in the salvage of patients with biochemical recurrent prostate cancer after prostatectomy $(79.7 \%$ of biochemical recurrence-free actuarial survival rate). Patients with pre-radiotherapy PSA $\leq 2 \mathrm{ng} / \mathrm{mL}$ have more biochemical control. We suggest reducing radiotherapy dose $<70$ Gy in $30 \%$ of the bladder volume and $<55$ Gy in $50 \%$ of the bladder volume to reduce the probability of acute and late urinary toxicity, respectively.

\section{CONFLICT OF INTEREST}

None declared. 


\section{REFERENCES}

1. Stephenson AJ, Shariat SF, Zelefsky MJ, Kattan MW, Butler EB, Teh BS, et al.: Salvage radiotherapy for recurrent prostate cancer after radical prostatectomy. JAMA. 2004; 291: 1325-32.

2. Cadeddu JA, Partin AW, DeWeese TL, Walsh PC: Long-term results of radiation therapy for prostate cancer recurrence following radical prostatectomy. J Urol. 1998; 159: 173-7; discussion 177-8.

3. Tsien C, Griffith KA, Sandler HM, McLaughlin P, Sanda MG, Montie J, et al.: Long-term results of threedimensional conformal adjuvant and salvage radiotherapy after radical prostatectomy. Urology. 2003; 62: 93-8.

4. Catton C, Gospodarowicz M, Warde P, Panzarella T, Catton P, McLean M, et al.: Adjuvant and salvage radiation therapy after radical prostatectomy for adenocarcinoma of the prostate. Radiother Oncol. 2001; 59: 51-60.

5. Bolla M, van Poppel H, Collette L, van Cangh P, Vekemans K, Da Pozzo L, et al.: Postoperative radiotherapy after radical prostatectomy: a randomised controlled trial (EORTC trial 22911). Lancet. 2005; 366: 572-8.

6. Common Terminology Criteria for Adverse Effects version 3. (http://ctep.cancer.gov/forms/ CTCAEv3.pdf) accessed in 09/06/2005.

7. Consensus statement: guidelines for PSA following radiation therapy. American Society for Therapeutic Radiology and Oncology Consensus Panel. Int J Radiat Oncol Biol Phys. 1997; 37: 1035-41.

8. Valicenti RK, Gomella LG, Perez CA: Radiation therapy after radical prostatectomy: a review of the issues and options. Semin Radiat Oncol. 2003; 13: 130-40.

9. Pound CR, Partin AW, Eisenberger MA, Chan DW, Pearson JD, Walsh PC: Natural history of progression after PSA elevation following radical prostatectomy. JAMA. 1999; 281: 1591-7.

10. Forman JD, Wharam MD, Lee DJ, Zinreich ES, Order SE: Definitive radiotherapy following prostatectomy: results and complications. Int J Radiat Oncol Biol Phys. 1986; 12: 185-9.

11. Katz MS, Zelefsky MJ, Venkatraman ES, Fuks Z, Hummer A, Leibel SA: Predictors of biochemical outcome with salvage conformal radiotherapy after radical prostatectomy for prostate cancer. J Clin Oncol. 2003; 21: 483-9.

12. Pollack A, Zagars GK, Starkschall G, Antolak JA, Lee JJ, Huang E, et al.: Prostate cancer radiation dose re- sponse: results of the M. D. Anderson phase III randomized trial. Int J Radiat Oncol Biol Phys. 2002; 53 : 1097-105.

13. Zelefsky MJ, Fuks Z, Hunt M, Lee HJ, Lombardi D, Ling CC, et al.: High dose radiation delivered by intensity modulated conformal radiotherapy improves the outcome of localized prostate cancer. J Urol. 2001; 166: 876-81. Erratum in: J Urol 2001; 166: 1839.

14. Macdonald OK, Schild SE, Vora SA, Andrews PE, Ferrigni RG, Novicki DE, et al.: Radiotherapy for men with isolated increase in serum prostate specific antigen after radical prostatectomy. J Urol. 2003; 170: 1833-7.

15. Maier J, Forman J, Tekyi-Mensah S, Bolton S, Patel $\mathrm{R}$, Pontes JE: Salvage radiation for a rising PSA following radical prostatectomy. Urol Oncol. 2004; 22: 50-6.

16. Roach M 3rd, DeSilvio M, Lawton C, Uhl V, Machtay M, Seider MJ, et al.: Phase III trial comparing wholepelvic versus prostate-only radiotherapy and neoadjuvant versus adjuvant combined androgen suppression: Radiation Therapy Oncology Group 9413. J Clin Oncol. 2003; 21: 1904-11.

17. Grossfeld GD, Stier DM, Flanders SC, Henning JM, Schonfeld W, Warolin K, et al.: Use of second treatment following definitive local therapy for prostate cancer: data from the caPSURE database. J Urol. 1998; 160: 1398-404.

18. Bahnson RR, Garnett JE, Grayhack JT: Adjuvant radiation therapy in stages $\mathrm{C}$ and $\mathrm{D} 1$ prostatic adenocarcinoma: preliminary results. Urology. 1986; 27: 4036.

19. Gibbons RP, Cole BS, Richardson RG, Correa RJ Jr, Brannen GE, Mason JT, et al.: Adjuvant radiotherapy following radical prostatectomy: results and complications. J Urol. 1986; 135: 65-8.

Accepted after revision: March 25, 2006 


\section{EDITORIAL COMMENT}

Unfortunately, there is no homogeneity in the works that compare salvage and adjuvant radiotherapies after radical prostatectomy. In the first group (adjuvant) all individuals are treated with radiotherapy, i.e., both favorable and unfavorable cases, however, in the second group (salvage only the cases with re- currence of the disease), are irradiated, obviously unfavorable cases and those with a higher risk of progression. This methodological problem presents an important bias, limiting the scientific relevance of these study designs.

Dr. Marcos Dall'Oglio

Division of Urology

University of Sao Paulo, USP

Sao Paulo, SP, Brazil

E-mail: marcosdallogliouro@terra.com.br 